\title{
Análisis crítico de la acción de no discriminación arbitraria a la luz de los primeros casos
} Non arbitrary discrimination action critical analysis

\author{
Lidia Casas Becerra \\ Universidad Diego Portales, Chile
}

Abogada de la Universidad Diego Portales (Chile). B.A. Regional and Urban Planning (Saskatchewan, Canadá) y candidata a doctora de la Universidad de Ottawa (Canadá). Miembro del Centro de Derechos Humanos de la Facultad de Derecho de la Universidad Diego Portales. Investigadora y profesora de la Facultad de Derecho de la Universidad Diego Portales desde el 2000. Ha realizados diversas investigaciones y publicaciones sobre derechos sexuales y reproductivos, aborto, violencia de género y administración de justicia. Ha trabajado en diversas organizaciones no gubernamentales tanto en Chile como en Canadá.

lidia.casas@udp.cl

\section{Catalina Lagos Tschorne}

Universidad de Chile, Chile

Abogada de la Universidad Diego Portales (Chile). Diplomada en "Derechos Humanos y Mujeres: Teoría y Práctica" y en "Derechos Indígenas, medioambiente y procesos de diálogo en el marco de la consulta del Convenio 169" por la Universidad de Chile. Estudios de Magíster en Derecho con mención en Derecho Público, Universidad de Chile. Se ha desempeñado como abogada de derechos humanos tramitando causas a nivel nacional, ante Ministros de Fuero y/o en Visita Extraordinaria, Cortes de Apelaciones, Corte Marcial y Corte Suprema; y a nivel internacional, ante la Comisión Interamericana y la Corte Interamericana de Derechos Humanos. Asimismo, tiene una sólida experiencia trabajando con los órganos del Sistema Universal de protección a los derechos humanos. Hasta el año 2013 formó parte del equipo jurídico de Corporación Humanas. Antes trabajó como abogada del Programa de Derechos Humanos del Ministerio del Interior. Actualmente se desempeña como coordinadora del Programa de Mujeres, Género y Derechos Humanos del Centro de Derechos Humanos de la Facultad de Derechos de la Universidad de Chile.

clagos@derecho.uchile.cl

\section{RESUMEN}

Tras la dictación de la Ley No. 20.609 (acción de no discriminación arbitraria), este artículo persigue identificar algunos de sus nudos críticos a través del estudio de las primeras sentencias que se han dictado en conocimiento de esta acción. Se presentan las deficiencias en que incurren los tribunales de justicia ya sea cuando se debe aplicar el test de discriminación o cuando se enfrentan a una colisión de derechos. Asimismo, se identifican a través del análisis de casos, los problemas que presenta la normativa en cuanto a las reglas de la carga de la prueba y la representación judicial.

Palabras clave: Acción de no discriminación arbitraria - igualdad y no discriminación -carga de la prueba - medidas especiales o afirmativas - juicio de ponderación - test de discriminación.

\begin{abstract}
This article identifies critical nodes of the nonarbitrary discrimination action (Law No. 20.609) by analysing early decisions adopted through this action. It presents Court's flaws in discrimination test application and rights clashes. Furthermore, it identifies normative problems within proves burden and legal representation by case analysis.
\end{abstract}

Key words: non arbitrary discrimination action equality and non-discrimination - burden of proof - special or affirmative measures - proportionality - discrimination test. 


\section{Introducción: Ley No. 20.609 que establece medidas contra la discriminación}

En julio de 2012 entró en vigencia la Ley No. 20.609 que establece medidas contra la discriminación, luego de 7 años de tramitación ante el Congreso Nacional'1.

Dicho cuerpo legal, en su artículo 1 establece "la acción de no discriminación arbitraria"2 regulada entre los artículos 3 y 14. Esta busca determinar si ha existido o no una discriminación arbitraria, y en caso afirmativo, ordenar se deje sin efecto el acto discriminatorio y disponer, ya sea su no reiteración, o bien que se realice el acto omitido (fijando un plazo perentorio prudencial para ello); pudiendo el/la juez/a adoptar otras medidas o providencias que estime necesarias a objeto de restablecer el imperio del derecho y asegurar la debida protección del afectado (artículo 12). Adicionalmente, el tribunal debe aplicar una multa de 5 a 50 Unidades Tributarias Mensuales (UTM) a las personas directamente responsables del acto u omisión discriminatorios, a beneficio fiscal.

La Ley, junto con crear una herramienta legal para restablecer el imperio del derecho frente a actos discriminatorios que ya se han materializado, también reforma otros cuerpos legales, siendo la más relevante la que incorpora una nueva circunstancia agravante en el artículo 12 del Código Penal para quienes cometan o participen en un delito motivados por determinados aspectos esenciales de la identidad de una persona que la ley expresamente identifica, tales como sexo, orientación sexual, identidad de género, raza, etnia, opinión política, entre otras.

A más de un año de la dictación de la Ley No. 20.609, el propósito de este artículo es revisar algunos de sus nudos críticos a la luz de las primeras sentencias que se han dictado en conocimiento de la acción de no discriminación arbitraria.

Para ello, se identificaron 42 causas iniciadas bajo el amparo de la Ley entre julio de 2012 y noviembre de 2013, a través de información entregada por la Corporación Administrativa del Poder Judicial (CAPJ). De estas, solo 12 estaban terminadas al 27 de noviembre, y solo 3 terminaron en sentencias definitivas ${ }^{3}$. En 2 casos las partes alcanzaron un acuerdo ${ }^{4}$, en 4 no se dio

* Agradecemos la valiosa colaboración de Natalia Arévalo, asistente de investigación del Centro de Derechos Humanos de la Facultad de Derecho de la Universidad de Chile, en la realización de este artículo.

Publicada en el Diario Oficial el 24 de julio de 2012.

La Ley utiliza la expresión "discriminación arbitraria", sin embargo, desde la perspectiva del Derecho Internacional de los Derechos Humanos (DIDH) puede entenderse que dicha expresión es redundante, puesto que el término "discriminación" se utiliza en un sentido restringido para denotar las diferenciaciones arbitrarias prohibidas y no en un sentido amplio, es decir, como sinónimo de "distinción" o de "diferenciación". Véase, PALACIOS, Patricia. La No Discriminación. Estudio de jurisprudencia del Comité de Derechos Humanos sobre la Cláusula Autónoma de No Discriminación, pp. 25-86. Disponible [en línea] <http://www.cdh.uchile.cl/media/publicaciones/pdf/7.pdf> [consulta: 14 de abril de 2014]. Sin perjuicio de lo anterior, mantendremos la nomenclatura que utiliza la ley para efectos de este artículo.

De acuerdo a lo informado por la CAPJ estas sentencias corresponden a las causas del $1^{\circ}$ Juzgado de Letras de Coyhaique. Rol 1325-2013; $15^{\circ}$ Juzgado Civil de Santiago. Rol 26206-2012 y; $14^{\circ}$ Juzgado Civil de Santiago. Rol 19997-2012. Sin embargo, esta información entregada por la CAPJ es incorrecta, puesto que la sentencia definitiva individualizada con el Rol 19997-2012, no corresponde a un caso iniciado mediante acción de no discriminación arbitraria, sino que más bien, a un caso de cobro de pesos.

$4 \quad 3^{\circ}$ Juzgado de Letras de Talca. Rol 726-2013 y Juzgado de Letras y Garantía de Licantén. Rol 98-2013. No se conoce la naturaleza del acto reclamado. 
curso a la demanda ${ }^{5}$ e en 3 se declaró la demanda como no presentada ${ }^{6}$.

El número de casos tramitados bajo la Ley es inexacto, pues refleja únicamente las acciones registradas por los tribunales bajo el código asignado a la acción de discriminación arbitraria (LO2-Discriminación). Estas investigadoras identificaron 3 sentencias que se tramitaron conforme a la Ley, pero que fueron registradas, por ejemplo, bajo el código de la acción de indemnización de perjuicios, de modo que no fueron contabilizadas por la CAPJ ${ }^{7}$. El análisis abarcará 5 sentencias definitivas, sin perjuicio de algunas precisiones y comentarios respecto de las resoluciones que no dan curso a la demanda o que la tienen por no presentada. Escapa el propósito de este trabajo indagar en las razones que pudieran explicar el bajo número de casos judicializados, pero es una pregunta que debe quedar planteada ante la constante búsqueda de respuestas en el derecho para la protección de los derechos humanos.

El estudio de las sentencias de término permite identificar varios puntos problemáticos, algunos referidos a las deficiencias que presenta la propia acción y otros en relación con la aplicación de dicha normativa. En particular, nos referiremos a los desafíos para los operadores de justicia tanto en la realización del juicio de ponderación en caso de colisión o conflicto de derechos, como en la aplicación del test de discriminación requerido para resolver estos conflictos. Sin embargo, este estudio no permite a las autoras obtener conclusiones generales sobre la aplicación de la Ley en general, considerando que aún existen otras 30 causas por definirse. Por lo mismo, las observaciones y conclusiones son respecto de cada caso y no se podrán extrapolar generalizaciones, ni menos aún tendencias jurisprudenciales, sino que simplemente constituyen una alerta sobre posibles tendencias contrarias a los estándares internacionales sobre derechos humanos.

\title{
1. La definición de "discriminación arbitraria" en la Ley No. 20.609
}

La Ley No. 20.609 en su artículo 2 define qué debe entenderse por discriminación arbitraria en los siguientes términos:

\begin{abstract}
[T]oda distinción, exclusión o restricción que carezca de justificación razonable, efectuada por agentes del Estado o particulares, y que cause privación, perturbación o amenaza en el ejercicio legítimo de los derechos fundamentales establecidos en la Constitución Política de la República o en los tratados internacionales sobre derechos humanos ratificados por Chile y que se encuentren vigentes, en particular cuando se funden en motivos tales como la raza o etnia, la nacionalidad, la situación socioeconómica, el idioma, la ideología u opinión política, la religión o creencia, la sindicación o participación en organizaciones gremiales o la falta de ellas, el sexo, la orientación sexual, la identidad de género, el estado civil, la edad, la filiación, la apariencia personal y la enfermedad o discapacidad.
\end{abstract}

Esta definición sigue de cerca la contenida en la Convención sobre la Eliminación de la Discriminación Racial y la Convención sobre la Eliminación de todas las Formas de Discriminación

De acuerdo a la CAPJ estas causas corresponden al $4^{\circ}$ Juzgado de Letras Civil de Antofagasta. Rol 5451-2013; $1^{\circ}$ Juzgado Civil de Santiago. Rol 10396-2013; $29^{\circ}$ Juzgado Civil de Santiago. Rol 4757-2013 y; $26^{\circ}$ Juzgado Civil de Santiago. Rol 6671-2013. Sin embargo, revisadas dichas resoluciones, pudimos constatar que la causa Rol 6671 2013 se tiene por no presentada.

$6^{\circ}$ Juzgado Civil de Santiago. Rol 24673-2012; $13^{\circ}$ Juzgado Civil de Santiago. Rol 10722-2013 y; $30^{\circ}$ Juzgado Civil de Santiago. Rol 29341-2012. El fundamento de las resoluciones judiciales es tener por no presentada las demandas en caso de no acompañar mandato judicial o acreditarse la calidad de abogado.

$3^{\circ}$ Juzgado Civil de Santiago. Sentencia de 5 de diciembre de 2012. Rol 17314-2012; $2^{\circ}$ Juzgado de Letras de Calama. Sentencia de 22 de julio de 2013. Rol 1502-2012 y; $22^{\circ}$ Juzgado Civil de Santiago. Sentencia de 25 de junio de 2013. Rol 20750-2012. 
en contra de las Mujeres. No obstante, agrega la limitación del ejercicio de este derecho por una justificación razonable, que como veremos, cobra especial relevancia en la ponderación de derechos.

\section{La carga de la prueba}

Uno de los problemas que enfrentan los justiciables frente a la discriminación es contar con elementos probatorios para acreditarla, lo que resulta gravoso cuando se produce en la privacidad, sin o con escasos registros de lo acontecido. En el caso Leyton $^{8}$, en que no se da curso a la demanda, el actor, funcionario de la Policía de Investigaciones de Chile, funda su pretensión en el rechazo que efectúa su superior del recurso de reclamación que había interpuesto con el fin de impugnar una medida disciplinaria impuesta con anterioridad, bajo el argumento de haber sido discriminado arbitrariamente al privarlo de una resolución fundada de dicho recurso.

Finalmente, el Tribunal al declarar la inadmisibilidad de la demanda, razona acerca de la falta de fundamentos y sobre la carencia de un ejercicio relacional, utilizando un análisis propio del concepto liberal de igualdad y no discriminación, al señalar que:

\footnotetext{
[...] el denunciante no indica de qué manera la falta de fundamentos alegada llega a configurar un acto de discriminación arbitraria, así como tampoco realiza un juicio comparativo entre la situación que dice afectarlo y situaciones idénticas o similares que hayan afectado a otras personas y respecto de las cuales se haya actuado distinto $[\ldots]^{9}$.
}

El problema del caso Leyton, es que la discriminación se produce sin que se expliciten las razones de la conducta y el tribunal no repara en que la falta de fundamento de una decisión constituye una puerta de entrada a la discrecionalidad, por lo cual la refuerza y luego le exige al justiciable que explique cómo se resolverían situaciones similares. El planteamiento generaría más obstáculos que el cuestionado acto discriminatorio. La comparación, así razonada, implicaría un problema de prueba no menor en casos que fueran menos manifiestos. Será el reclamante quien deba realizar el ejercicio, obtener la información para construir el caso y aportarla para probar la discriminación, lo cual en muchos casos no es de fácil acceso ${ }^{10}$. Para algunos podría significar, por ejemplo, demostrar que todas las personas que comparten ciertas características son tratadas de la misma manera. Si un trabajador es violentado con epítetos que hacen referencia a su origen racial, la defensa podría sostener que el hecho no tendría motivación discriminatoria, pues en la empresa hay otros trabajadores, que compartiendo las mismas características, no son sujetos de un supuesto maltrato o discriminación ${ }^{11}$. Demás está decir, que esta forma de construcción del ejercicio comparativo es rechazada, pues no se trata de que todos los sujetos pertenecientes a una clase sean tratados de igual manera para que se produzca un hecho discriminatorio, sino que la lesión o el menoscabo se produzca a una persona determinada en cierto contexto.

La Ley debió adoptar una regla sobre la carga de la prueba, mecanismo disponible, por ejemplo, en la acción de tutela laboral. Ello permite incorporar en el análisis del caso los indicios sobre la conducta denunciada de lesión de derechos fundamentales, lo que obligaría al demandado

$29^{\circ}$ Juzgado Civil de Santiago. Caso Leyton. Sentencia de 9 de mayo de 2013. Rol C-4757-2013.

Ibídem, considerando 3.

10

Piénsese por ejemplo en la acción de reclamación por igualdad salarial entre hombres y mujeres prevista en la Ley No. 20.348 que resguarda el derecho a la igualdad en las remuneraciones.

11 Véase, por ejemplo, $2^{\circ}$ Juzgado del Trabajo de Santiago. Dirección General del Trabajo con Envases Exportables Ltda. Sentencia 23 de marzo de 2011. Rol T-403-2010. 
explicar las razones de su conducta ${ }^{12}$.

Sin perjuicio de ello, y pese a la ausencia de una norma expresa, debe entenderse que en conformidad al DIDH, "[a]creditado el empleo de una clasificación sospechosa, la inversión de la carga justificatoria pone en cabeza del Estado la fundamentación de la medida impugnada. Cabe entonces al Estado demostrar las razones concretas que condujeron a acudir a dicha clasificación para establecer una distinción legal"13. Justamente en ese sentido argumentó la Corte Interamericana de Derechos Humanos (Corte IDH) en el caso Atala Riffo y niñas vs. Chile ${ }^{14}$.

\section{La efectividad de la acción para conocer casos de discriminación por falta de adopción de medidas especiales o afirmativas}

En el caso Castillo ${ }^{15}$, el denunciante alegó que al concurrir a un recinto penitenciario para realizar una visita se le negó la posibilidad de ingresar en primer lugar. Un gendarme le indicó que no por estar en silla de ruedas tendría preferencia para ingresar. El afectado informó a Gendarmería de lo ocurrido, y posteriormente, cuando realizó una nueva visita, el mismo gendarme lo volvió a increpar, enviándolo al final de la fila, tras lo cual el denunciante se retiró, para luego volver en compañía de Carabineros, con quienes logró ingresar al recinto. En este caso, el tribunal se preguntó si el acto era discriminatorio o una manifestación de otro fenómeno.

En definitiva, el juez resolvió que la denuncia no se enmarcaba en los términos del artículo 2 de la Ley, rechazándola, por considerar que:

[...] finalmente lo reclamado obedece más bien y "contradictoriamente" a no haberse discriminado -positivamente- y por ende permitir un ingreso preferente al denunciante al C.D.P. de esta ciudad, en razón de su discapacidad; así las cosas, en estos antecedentes no existió una restricción, distinción o exclusión que privara del ejercicio de un derecho legítimo al denunciante, y que sea sancionable a través de la presente ley, que es restrictivamente lo llamado a resolverse por este tribunal, más allá de las normas de trato y respeto mutuo que deben existir en las relaciones humanas ${ }^{16}$.

Más allá de los hechos del caso concreto, resulta ilustrativo el razonamiento del juez en el sentido de que mediante la acción de no discriminación, solo se puede determinar la existencia de una restricción, distinción o exclusión, sin poder pronunciarse sobre la falta de adopción de medidas especiales.

Llama la atención que el juez utilice el término "contradictoriamente", puesto que de ello podría inferirse que la falta de adopción de medidas especiales -o de "discriminación positiva" en sus palabras- no podría constituir una vulneración al principio de igualdad y no discriminación. Consideramos que sería interesante plantearse qué habría resuelto el tribunal si el denunciante hubiese alegado la inexistencia de rampas para acceder al recinto. La situación anterior es la que paradigmáticamente se advierte en casos de discriminación, la obstaculización -directa o indirecta- de ingreso por las capacidades de movimiento de una persona. Sin embargo, la noción de

\footnotetext{
12 Véase artículo 493 del Código del Trabajo.

13 DULITZKY, Ariel. "Claroscuros de la jurisprudencia interamericana". En: CAICENDO, Danilo y PORRAS, Angélica. (Eds.) Igualdad y no discriminación. El reto de la diversidad. Quito: Ministerio de Justicia, Derechos Humanos y Cultos, 2010, p. 590. Corte IDH. Caso Atala Riffo y niñas vs. Chile. Fondo, Reparaciones y Costas. Sentencia de 24 de septiembre de 2012. Serie C No. 239, párr. 124.

$152{ }^{\circ}$ Juzgado de Letras de Calama. Caso Castillo. Sentencia de 22 de julio de 2013. Rol C-1502-2012.

16 Ibídem, considerando 4.
} 
discriminación no se agota allí. Las dificultades de desplazamiento en el espacio público y privado resulta más gravosa para quien usa una silla de ruedas o tiene dificultad de movilidad. No es que se haya privado de acceso, sino que el uso del espacio es obstaculizado teniendo como base una visión de igualdad de trato "todos a la fila". Esta no considera elementos estructurales de discriminación ni acciones positivas para revertir situaciones de desigualdad, manteniendo el parámetro de comparación en la normalidad y limitando la eficacia que una norma de estas características debiera tener para hacer frente al menoscabo de derechos.

El tribunal, sin entender los elementos substantivos de la igualdad, rechaza la acción para establecer que solo existe una infracción a las normas de trato y respeto mutuo que deben existir en las relaciones humanas, que en este caso tiene a su base la discriminación y el reclamo por el ejercicio de un derecho.

Una interpretación pro persona de este cuerpo legal, que busque darle un efecto útil, y que permita garantizar de manera efectiva el goce y ejercicio del derecho a la igualdad y no discriminación, debe conducir a la conclusión de que la acción de no discriminación sí permite al tribunal conocer, declarar y revertir situaciones de desigualdad originadas por la falta de adopción de medidas especiales. En efecto, la Ley No. 20.609 faculta ampliamente al juez o jueza para adoptar "las demás providencias que juzgue necesarias para restablecer el imperio del derecho y asegurar la debida protección del afectado"17.

\section{La realización del juicio de ponderación en caso de colisión o conflicto de derechos}

El inciso tercero del artículo 2 de la Ley No. 20.609 (que -como ya señalamos- establece la definición de discriminación) dispone lo siguiente:

\footnotetext{
Se considerarán razonables las distinciones, exclusiones o restricciones que, no obstante fundarse en alguno de los criterios mencionados en el inciso primero, se encuentren justificadas en el ejercicio legítimo de otro derecho fundamental, en especial los referidos en los números $4^{\circ}, 6^{\circ}, 11^{\circ}, 12^{\circ}, 15^{\circ}, 16^{\circ}$ y $21^{\circ}$ del artículo 19 de la Constitución Política de la República, o en otra causa constitucionalmente legítima.
}

Esta norma fue objeto de innumerables discusiones durante su tramitación. En primer lugar, la propuesta original consideraba que no constituiría discriminación cuando las entidades religiosas hicieran la distinción en base a las actividades que desarrollan. Esta visión fue rechazada, pues la excepción expresa a favor de iglesias no podría ser justificada constitucionalmente, por lo cual debiese realizarse una correspondiente ponderación de derechos ${ }^{18}$.

En segundo lugar, la discusión se centró en el alcance de lo que se podría considerar como "siempre razonable" al momento de realizar distinciones, exclusiones o restricciones justificadas por el legítimo ejercicio de otro derecho fundamental ${ }^{19}$. Finalmente, la expresión "siempre" fue eliminada de la redacción ${ }^{20}$. Dentro de los argumentos para eliminar el vocablo, se encuentra el que resultaba innecesario, y que en virtud de él se podría considerar que la norma equivalía a una presunción de derecho. Ahora bien, también se sostuvo que lo que debía eliminarse era el párrafo completo, ya que ni aún con la eliminación de la palabra "siempre" se lograría

Artículo 12, inciso primero.

18 Biblioteca del Congreso Nacional de Chile. Historia de la Ley No. 20.609, p.733 y pp. 677-679. Disponible [en línea] <http://www.leychile.cl/Navegar?idNorma=1042092> [consulta: 14 de abril de 2014]. Patricio Zapata propuso la inclusión de la ponderación en la norma.

Ibídem, p.780.

lbídem, p.1130. 
alterar la jerarquización de derechos que dicho precepto consagra ${ }^{21}$. En un sentido similar, organizaciones de la sociedad civil plantearon luego de la adopción de la ley, que el inciso tercero del artículo 2 establece "una jerarquía a derechos inadmisible que rebaja a los derechos a la igualdad y a la no discriminación a derechos de segundo orden"22; de allí que sea tan importante observar cómo los tribunales la interpretarán.

En la sentencia del caso Zapata ${ }^{23}$, la primera dictada en conocimiento de la acción de no discriminación arbitraria que ha sido acogida favorablemente por los tribunales de justicia -y probablemente la única-, la jueza debió hacerse cargo de aplicar esta cuestionada norma. En este caso, a una pareja de lesbianas que acudió a un motel se les negó el uso de las habitaciones, a pesar de haber disponibilidad. Al exigir que se explicitara el motivo de esta negativa, se les respondió que "por políticas de la empresa no pueden ingresar por ser ustedes". Ante esta situación, las afectadas exigieron hablar con el encargado y realizar un reclamo, lo que les fue negado, indicándoles un lugar donde sí las dejarían entrar. Frente a ello, reclamaron judicialmente por el acto discriminatorio basado en su orientación sexual. La demandada alegó que no había ejercido tal acto, y -contradiciéndose- que encontraba justificación en el ejercicio del derecho reconocido en el artículo 19 No. 21 de la Constitución Política de la República (CPR), es decir, el derecho a desarrollar actividades económicas.

El tribunal concluyó que hubo una acción discriminatoria que no tiene justificación en el derecho a desarrollar actividades económicas, y que por lo tanto era arbitraria. Es interesante analizar la cadena argumentativa del tribunal para arribar a dicha conclusión.

La sentencia señala que el recurrido alegó como justificación del trato diferenciado el legítimo ejercicio de la garantía del artículo 19 número 21 de la CPR, "el derecho a desarrollar cualquiera actividad económica que no sea contraria a la moral, al orden público o a la seguridad nacional, respetando las normas legales que la regulen", señalando:

\footnotetext{
[E] Hotel Marín 014, desde el año 1988 ha procurado satisfacer las necesidades de su clientela, la cual ha sido y es mayoritariamente heterosexual. Para lo anterior, el Hotel se ha esmerado en acondicionar sus instalaciones y servicios para atender de la mejor manera a sus clientes. Tanto la ambientación, el diseño, la música, los muebles y otros detalles son pensados y orientados hacia el público heterosexual. Todo lo anterior es perfectamente lícito y está amparado por el Art. 19 № 21 de la Constitución Política de la República. Se trata de normas que amparan el derecho de nuestra representada para desarrollar cualquier actividad económica ${ }^{24}$.
}

El tribunal razonó, en primer lugar, que el recurrente se contradice a sí mismo al sostener que de todas formas permiten el acceso de parejas homosexuales al recinto pese a que existen "otros establecimientos que están en condiciones de brindarles un mejor servicio, ya que están preparados y especialmente acondicionados para atender a parejas homosexuales" 25 . El tribunal sostiene que causa extrañeza esta afirmación por cuanto se ignora qué acondicionamiento especial o preparación adicional requeriría una habitación de motel para que una pareja homosexual concurriera a dicho recinto -además del mobiliario y servicios higiénicos-, por lo que desestima la fundamentación del recurrido. En segundo lugar, sostuvo que no basta con invocar un dere-

\footnotetext{
21 Ibídem, pp. 1116-1130.

22 MATURANA, Camila. Observatorio Parlamentario. Balance al Poder Legislativo Año 2012. Santiago de Chile: Andros impresores, 2013.

$23 \quad 3^{\circ}$ Juzgado Civil de Santiago. Caso Zapata. Sentencia de 5 de diciembre de 2012. Rol C-17314-2012.

24 Ibídem, considerando 16, párrafo primero.

25 Ibídem, considerando 2, párrafo final.
} 
cho fundamental como justificación, sino que es necesario acreditar su ejercicio legítimo. La pregunta es si el ejercicio de este a la luz del mandato de la Constitución -artículo 19 No. 21- y las leyes, puede no someterse a los tratados internacionales sobre derechos humanos ratificados y vigentes por Chile.

En atención a lo anterior, la magistrada resuelve que la acción discriminatoria ejecutada por la sociedad reviste el carácter de arbitraria, ya que no nos encontramos en presencia de una "distinción, exclusión o restricción" razonable, fundada en el derecho que le reconoce al efecto el artículo 19 No. 21 de la Constitución Política de la República, pues el permitir el acceso solo a parejas heterosexuales no encuentra justificación alguna en relación al giro de la sociedad. Agrega que pensar de tal modo importaría avalar constantes actos de discriminación, consistentes, por ejemplo, que en un restaurante no se permitiera el ingreso de parejas homosexuales, lo que repugna al principio de igualdad ante la ley y la necesaria tolerancia y aceptación que deben existir entre los seres humanos.

La magistrada enuncia un camino argumentativo adecuado para solucionar el problema que se le plantea. Sin embargo, el razonamiento final no es del todo apropiado, en cuanto fundamenta la falta de razonabilidad de la acción ejecutada en no encontrar su justificación en el giro de la sociedad. Frente a ello cabe preguntarse qué habría resuelto el tribunal si el giro social hubiese limitado la atención únicamente de parejas heterosexuales. En efecto, este tipo de razonamiento llevaría a legitimar, por ejemplo, la cancelación de la matrícula de una estudiante embarazada, por estar previsto en el reglamento interno del establecimiento educacional en el ejercicio legítimo de un derecho: la libertad de enseñanza y la libertad para desarrollar una actividad económica $^{26}$. En este sentido, la argumentación no debió atender al giro de la sociedad, sino que a la afectación de los derechos y su importancia de satisfacción.

De esta manera, el tribunal para hacer frente a este u otro conflicto de derechos, debió realizar un juicio de ponderación, sopesando ambos derechos que entran en colisión, a fin de determinar cuál de ellos tiene mayor peso en circunstancias específicas. Esta actividad según Alexy, distingue tres elementos: la fórmula del peso, que tiene por objeto determinar la intensidad de la afectación en un derecho ${ }^{27}$, el juicio de ponderación, el cual consiste en establecer el grado de detrimento del primer derecho, posteriormente determinar la importancia de satisfacer el segundo derecho y finalmente establecer si dicha satisfacción justifica la no satisfacción del primero. Y por último, la carga de argumentación, la cual se da en los casos que concluyen con un empate entre los derechos en conflicto, debiendo tomar una decisión justificada racionalmente ${ }^{28}$.

\section{La aplicación del test de discriminación por parte de los tribunales nacionales}

La jurisprudencia internacional y la doctrina han coincidido en que no todo trato diferenciado constituye discriminación, y que un trato diferenciado para ser legítimo requiere tener una justificación objetiva y razonable y perseguir un fin legítimo ${ }^{29}$.

26 A este respecto, es pertinente recordar el caso Carabantes vs. Chile ante la Comisión Interamericana de Derechos Humanos en que Chile alcanzó un acuerdo amistoso por la discriminación sufrida y refrendada por la Corte Suprema. Véase, CIDH. Caso Carabantes con Chile, petición 12.046, 12 de marzo de 2002.

27 ALEXY, Robert. "Epílogo a la Teoría de los Derechos Fundamentales". Revista Española de Derecho Constitucional, No. 66, 2002, p. 41.

ALEXY, Robert. "Los derechos constitucionales y el sistema jurídico". En: Teoría del discurso y derechos constitucionales. Cátedra Ernesto Garzón Valdés. México: Editorial Fontamara, 2005, pp.78-87. manos". En: NASH, Claudio y MUJICA, Ignacio (Eds.). Derechos Humanos y Juicio Justo. Lima: COLAM, 2010, p. 169 y, PALACIOS, Patricia. La no discriminación. Santiago: Centro de Derechos Humanos Facultad de Derecho Universidad de Chile, 2006, pp.34-35. 
De este modo, cuando los tribunales de justicia se encuentren ante un potencial caso de discriminación, será preciso que a lo menos se busque determinar que la distinción impugnada es objetiva, razonable y persigue un propósito legítimo. Para esto será necesario que los tribunales identifiquen previamente: la existencia de un trato diferenciado, cuál es el criterio o categoría para diferenciar y qué se persigue con la distinción. Teniendo estos antecedentes, se requiere que el criterio de la diferenciación sea objetivo, que la distinción sea razonable, que el fin perseguido sea legítimo con arreglo a los tratados internacionales de DDHH y que por supuesto, la medida sea necesaria y conducente para alcanzar dicho fin, esto es, que sea proporcional ${ }^{30}$.

Sin embargo, el desarrollo jurisprudencial desde la aprobación de la Ley No. 20.609 no ha sido uniforme en sus criterios para determinar la existencia de discriminación arbitraria. Es así como en la primera sentencia favorable a las víctimas de discriminación, se realiza un análisis acertado en una primera etapa, buscando el tribunal la acreditación de la acción supuestamente discriminatoria y de sus fundamentos ${ }^{31}$, pero al enfrentarse a una colisión de derechos ante la argumentación de que la distinción de trato se encontraría amparada en una norma constitucional (artículo 19 No. 21), abandona el análisis del acto discriminatorio, terminándolo abruptamente al establecer que "el permitir el acceso sólo a parejas heterosexuales no encuentra justificación alguna en relación al giro de la sociedad" ${ }^{32}$, situando la justificación razonable en un giro comercial.

Por otra parte, en el caso Ortiz ${ }^{33}$, el actor fundó su pretensión en la tramitación de la denuncia investigada por Fiscalía por el delito de lesiones menos graves en contexto de violencia intrafamiliar en contra de su cónyuge mujer, cuya denuncia por el mismo hecho derivó en la concesión de medidas cautelares y en la formalización de la investigación. Por su parte, la denuncia del actor derivó en el archivo provisional de la causa y posteriormente en el rechazo de medidas cautelares, lo cual a su parecer constituyó una actuación de discriminación arbitraria por parte del Ministerio Público, basada en el sexo $^{34}$. Frente a estos hechos el tribunal hace un análisis más detallado del acto discriminatorio, teniendo como propósito "la determinación de la existencia de una distinción, exclusión o restricción que carezca de justificación razonable ${ }^{\prime \prime 35}$, pero en ningún caso llega a cuestionarse la proporcionalidad de la medida, ya que a juicio del tribunal, no siempre se debe hacer este ejercicio, sino solo cuando la "situación lo amerita" ${ }^{36}$, quedando relegada la necesidad y conducencia de la distinción.

30 NASH, Claudio y DAVID, Valeska. Igualdad y no discriminación... op.cit, p. 169 y, BAYEFSKY, Anne. "El principio de igualdad o no discriminación en el derecho internacional". Human Rights Law Journal, Vol.11, No. 1-2, 1990, p. 12.

$3^{\circ}$ Juzgado Civil de Santiago. Caso Zapata, op.cit., considerando 14.

32 Ibídem, considerando 19.

$12^{\circ}$ Juzgado Civil de Santiago. Caso Ortiz. Sentencia de 25 de junio de 2012. Rol C-20750-2012.

En la denuncia, el actor utiliza la expresión "identidad de género" y no "sexo" para identificar el motivo de discriminación en que se fundó el alegado acto discriminatorio. Sin embargo, se trata de una confusión conceptual del recurrente, ya que la "identidad de género" se refiere a "la vivencia interna e individual del género tal como cada persona la siente profundamente, la cual podría corresponder o no con el sexo asignado al momento del nacimiento, incluyendo la vivencia personal del cuerpo (que podría involucrar la modificación de la apariencia o la función corporal a través de medios médicos, quirúrgicos o de otra índole, siempre que la misma sea libremente escogida) y otras expresiones de género, incluyendo la vestimenta, el modo de hablar y los modales" (Principios de Yogyakarta. Principios sobre la aplicación de la legislación internacional de derechos humanos en relación con la orientación sexual y la identidad de género, 2006). Al tenor de los hechos relatados es posible señalar que el motivo de discriminación alegado es el sexo, puesto que el denunciante sostiene haber recibido un trato diferenciado en relación con su cónyuge, por ser el hombre y ella mujer.

$3512^{\circ}$ Juzgado Civil de Santiago. Caso Ortiz, op.cit., considerando 11.

$36 \quad$ Ibídem, considerando 19. 
Igualmente, en el caso Morandé ${ }^{37}$, el actor alegó un rechazo injustificado de su postulación a becas de magíster del programa de Becas Chile, declarada "fuera de bases" por no superar el examen formal de postulación. Lo cual significó, según este, un acto de discriminación arbitraria. Ante estos antecedentes, el tribunal realizó una incompleta aplicación del test de discriminación, en el que si bien se identifica el acto alegado como discriminatorio, considerándolo razonable por el tribunal, no se refiere a la objetividad de este, ni al fin legítimo, ni tampoco realiza un ejercicio proporcional, centrándose finalmente en que la acción de no discriminación debe sustentarse en las categorías "previstas por la ley u otra" ${ }^{38}$, lo que no había sido acreditado en el presente caso.

\section{La exigencia del patrocinio de un abogado habilitado para el ejercicio de la profesión}

En los casos roles $6671-2013^{39}, 10722-2013^{40}, 24673-2012^{41}$ y $29341-2012^{42}$, los tribunales no se pronunciaron sobre el fondo del asunto planteado mediante la acción de no discriminación, sino que resolvieron que ninguna de estas demandas se tendrían por presentadas, es decir, se hizo efectivo el apercibimiento del artículo 2 la Ley No. 18.120, que exige la constitución de mandato judicial o patrocinio para proveer la demanda, según lo dispuesto en el artículo 1 del mismo cuerpo legal.

Esta será una cuestión a reflexionar, considerando que la tramitación de la acción de protección permite discutir cuestiones de discriminación y no exige tal mandato. Si lo que se pretende es mayor acceso a la justicia, la constitución de un mandato la obstaculiza. La mera dictación de una ley no cambia realidades, pero puede ser transformativa cuando se acompaña de diseños institucionales y prácticas que permitan un mayor acceso a la justicia.

\section{Conclusiones}

Este trabajo busca encontrar luces sobre los criterios que utilizan los jueces para resolver los casos de discriminación. Aquí presentamos algunos hallazgos que no son más que alertas. Si bien se vislumbra un esfuerzo de los tribunales en identificar los actos discriminatorios y su justificación razonable, ello resulta insuficiente si se abandonan elementos necesarios para dar un completo y correcto análisis de las situaciones que vulneran la igualdad.

Resulta preocupante conocer la escasa utilización de la ley, las razones de esta situación escapan los propósitos de este artículo. Sin embargo, cualquier intento por proteger de mejor forma los derechos de las personas debe obligarnos a pensar no solo en el rol de los jueces, sino las instituciones que diseñamos para ello. Si la cultura legal impone fuertes cargas probatorias, o se realizan exámenes incompletos sobre la justificación de la conculcación de derechos o se imponen cargas en la litigación, las posibilidades del uso del derecho y su éxito para modificar pautas culturales serán reducidas. Ahora bien, y tal como se planteó en las líneas precedentes, es necesario reiterar que algunos de los problemas que presenta la Ley No. 20.609 pueden corregirse sin necesidad de reformas legislativas, sino que efectuando una interpretación pro persona

\footnotetext{
$37 \quad 15^{\circ}$ Juzgado Civil de Santiago. Caso Morandé. Sentencia de 18 de julio de 2013. Rol C-26206-2012.

$38 \quad$ Ibídem, considerando 11.

$3926^{\circ}$ Juzgado Civil de Santiago. Resolución de 28 de mayo de 2013. Rol C-6671-2013. De acuerdo a la información entregada por la CAPJ en esta causa no se habría dado curso a la demanda, sin embargo, se trata de un caso en el que la demanda se tiene por no presentada.

$40 \quad 13^{\circ}$ Juzgado Civil de Santiago. Resolución de 2 de agosto de 2013. Rol C-10722-2013.

$41 \quad 6^{\circ}$ Juzgado Civil de Santiago. Resolución de 29 de enero de 2013. Rol C-24673-2012.

$4230^{\circ}$ Juzgado Civil de Santiago. Resolución de 9 de enero de 2013. Rol C-29341-2012.
} 
y de buena fe de la normativa.

Reflexionar sobre una ley o su eficacia no es solo una cuestión del mecanismo o los desincentivos, como fuera la existencia de una multa para el demandante que obre sin fundamentos. Implica pensar en la credibilidad del Derecho y sus instituciones. Cualesquiera que fuera(n) la(s) respuesta(s) a esto amerita pensar que la búsqueda de igualdad es un proceso y no únicamente la búsqueda de hitos como la promulgación de una ley. 
